work-up before initiating treatment, defines the treatment goals, and improves control. The use of a problem-orientated summary card in addition seems to achieve most of the objectives attempted in the computer-held record system. For research perhaps manual handling of notes is still necessary, but recall of information is much simplified, as compared with unstructured notes.

The problem-orientated record system has the advantage that it is very inexpensive and can be used by both general practices and hospitals which have no access to computers.

Abbot's Langley,
Herts

P R V Tomson

SIR,-In the discussion of their work on computer-held records of hypertensive patients Dr C J Bulpitt and his colleagues (20 March, p 677) compare their computer system with the clerical retrieval from standard notes. However, many of the advantages they have found using the computer could be achieved using a simpler approach-for example, punched feature cards. ${ }^{1}$ We have used punched feature cards in a general practice of 10000 patients for three years ${ }^{2}$ and, should it prove necessary, they can be used as an input to a computer. ${ }^{3}$

The false logic of "a computer can solve our problems, therefore we should use a computer to solve our problems" appears to be all too common. Perhaps more attention should be paid to simple, less expensive, and more flexible information handling systems, of which punched feature cards are an outstanding example.

Centre for Medical Education, University of Dundee

\section{RONALD HARDEN}

Bearsden,

KENNETH HARDEN

Glasgow

Harden, R McG, et al, British fournal of Hospital Medicine, 1975, 13, 195

Harden, K A, Harden, R McG, and Reekie, D, British Medical fournal, 1974, 2, 162.

Royal College of General Practitioners, $1975,25,143$.

\section{Recurrent haematuria}

SIR,-The paper by Dr J Michael and his colleagues from St Thomas's Hospital on unexplained recurrent haematuria (20 March, p 686) comes as a welcome addition to the literature on this important subject. However, one or two points deserve comment.

I have never questioned the value of renal biopsy in the syndrome of recurrent or persistent haematuria, only its justification and practicability as a routine in such patients. Unexplained haematuria remains a large group in most disease indices, being second in magnitude (25 cases) in Burkholder's group of haematuria cases ${ }^{1}$ and making up $5-10 \%$ of all patients with haematuria in the Manchester review. ${ }^{2}$ Leaving aside economic and temporal factors it seems unlikely, should this incidence be reflected nation-wide, that facilities exist for the efficient performance of renal biopsy and the accurate interpretation of the histological and immunofluorescent findings in every patient falling into this group. The pursuit of a diagnosis, especially if it prevents needless over-investigation, is to be applauded; it was Burkholder's contention-rightly so, I feel- that invasive investigations with a recognised morbidity which do not lead to any significant change in patient treatment might be open to criticism.

Furthermore, the average age in the $S t$ Thomas's group was 25 years-an age group in which renal biopsy might be expected to yield a high incidence of abnormalities reflecting the high incidence of so-called focal nephritis in young adults with haematuria. The average age in the Manchester review was 50 years, in which group the search for incipient malignant disease is a more significan problem and in which renal biopsy might not play such a useful role.

This said, however, the results from $S t$ Thomas's certainly complement those from other centres investigating the younger groups of recurrent haematuria and, with those of Higgins and $\mathrm{Aber},{ }^{3}$ seem to indicate the diag nosis, in the young male patient with this complaint, of mesangial IgA nephropathy, with its apparent independence from the haematuria/loin pain syndrome, of possible renovascular origin, occurring more commonly in the female. This may well represent significant step forward in the clarification of this important disease complex and its management.

\section{PATRICK H O'ReILLY}

Manchester Royal Infirmary,

hester

Burkholder, G V, et al, fournal of the American Medical Association, 1969, 210, 1729.

(1974 (U)

Urology, 1974, 46, 601 .

\section{Propranolol and the nephrotic syndrome}

SIR,-In a recent report (12 April 1975, p 68) my colleagues and I described a patient who had developed the nephrotic syndrome in association with practolol therapy. In the same patient propranolol was substituted for practolol in a dosage of $40 \mathrm{mg}$ daily for 10 months and $160 \mathrm{mg}$ daily for another six months. Vague circumscribed psoriasiform skin lesions on the arms and a proteinuria of $2 \mathrm{~g} / 24 \mathrm{~h}$ were then detected. No urinary protein had been detected on routine examination during the previous months. The propranolol was stopped, but four weeks later the patient developed a severe normotensive nephrotic syndrome with a proteinuria of $21 \mathrm{~g} / 24 \mathrm{~h}$, urinary casts, no excess of urinary red or white cells, a creatinine clearance of $70 \mathrm{ml} / \mathrm{min}$, and a serum albumin concentration of $26 \mathrm{~g} / 1$. Tests for antinuclear factor in the serum were negative.

Treatment with prednisolone, initially $60 \mathrm{mg}$ daily, was instituted six weeks after stopping the propranolol therapy because of persistent severe proteinuria. After three weeks the urine contained only a trace of protein and the serum albumin level was $35 \mathrm{~g} / 1$. Two weeks later the urinary protein was quantitatively normal and the creatinine clearance was $82 \mathrm{ml} / \mathrm{min}$. The rash had also resolved.

It was assumed that the propranolol had induced a minimal-change glomerulonephritis, as the practolol had done. This diagnosis was not confirmed by a second renal biopsy, although it was supported by the excellent and swift improvement with prednisolone. $\mathrm{Al}$ though practolol and propranolol are different chemically, they both act as beta-blockers and, in this man's case, they both appear to be capable of inducing a nephrotic syndrome.

Department of Nephrology, Hull Royal Infirmary (Sutton)
Hull

M J FARR

\section{Bottle-feeding and tummy-ache in infants}

SIR,-Newborn babies commonly have tummy-ache. The infant cries incessantly, will not be comforted, flexes his legs, and continually seeks the breast, although his sucking is frequently interrupted by spasms of distress The syndrome is conventionally ascribed (without evidence) to "wind," and since it is maximal at around one week of age-shortly after discharge from hospital-tends not to come to the notice of the doctor. The mother and her advisers frequently interpret the signs as resulting from under-feeding and hunger, and this is a major factor in the customary decision to abandon breast-feeding. ${ }^{1}$

Virtually all hospital-born babies receive feeds of cow's milk for the first 1-3 nights of life, even if they are subsequently to be breast-fed. Cow's milk is antigenic and evokes an antibody response in normal bottle-fed neonates. ${ }^{2}$ A local immune response in the gut would be associated with hyperplasia of the mesenteric lymph nodes and Peyer's patches, with inflammation and hyperperistalsis leading perhaps, in exceptionally severe cases, to intussusception. The timing of the syndrome is just right for primary immune response.

Total avoidance of cow's milk in neonatal life has been advocated ${ }^{3}$ as a means of preventing atopy. I suggest that it would also avoid "wind" and greatly increase the likelihood of successful breast-feeding.

DAVID FREED

Immunology Laboratories,

Dacteriology and Virology,

University of Manchester 'Davies, D P, and Thomas, C, Lancet, 1976, 1, 420.
Truelove, S C, and Jewell, D P, in Clinical Aspects of
Immunology, ed P G H Gell, R R A Coombs, and
P J Lachmann. Oxford, Blackwell, 1975.
3 Soothill, J F, et al, British Society for Allergy and
Clinical Immunology, Oxford meeting, 13 Decem-
ber 1975 .

\section{Amoebic meningoencephalitis in Britain}

SIR,-Dr J L Griffin (17 January, p 153) has suggested that in our case of amoebic meningoencephalitis ${ }^{1}$ an acanthamoeba (which was not isolated) must have been the primary pathogen, the Naegleria gruberi which was isolated from the cerebrospinal fluid $(\mathrm{CSF})^{2}$ being a secondary invader.

We agree that in the CSF the amoebae which were seen resembled acanthamoebae more than naegleriae, although naegleriae can move slowly and produce spiky pseudopods. ${ }^{3}$ Dr Griffin suggests that culture for acanthamoebae from the CSF should have been done immediately. In fact, although not mentioned in our papers, this was done in this laboratory but no amoebae were isolated. Immediately after collection the first specimen of CSF from case 1 in which amoebae were seen (two days after admission) was inoculated on to klebsiella-agar plates and into $\mathrm{HeLa}$ cell cultures, both of which had previously been found suitable in this laboratory for the growth of acanthamoebae. The surface of the agar was of a dryness known to be suitable for the growth of acanthamoebae, although this degree of dryness was found subsequently to be unsuitable for the growth of naegleriae. The day after collection this CSF 